\title{
Nanosized soy phytosome-based thermogel as topical anti-obesity formulation: an approach for acceptable level of evidence of an effective novel herbal weight loss product
}

This article was published in the following Dove Press journal:

International Journal of Nanomedicine

\section{Shahira F El-Menshawe,' Adel A Ali,' Mohamed A Rabeh, ${ }^{2}$ Nermeen $M$ Khalil $^{3}$ \\ 'Department of Pharmaceutics and Industrial Pharmacy, Faculty of Pharmacy, Beni-Suef University, Beni Suef, ${ }^{2}$ Department of Pharmacognosy, Faculty of Pharmacy, Cairo University, Giza, ${ }^{3}$ Department of Pharmaceutics and Clinical Pharmacy, Faculty of Pharmacy, Nahda University Beni-Suef, Beni Suef, Egypt}

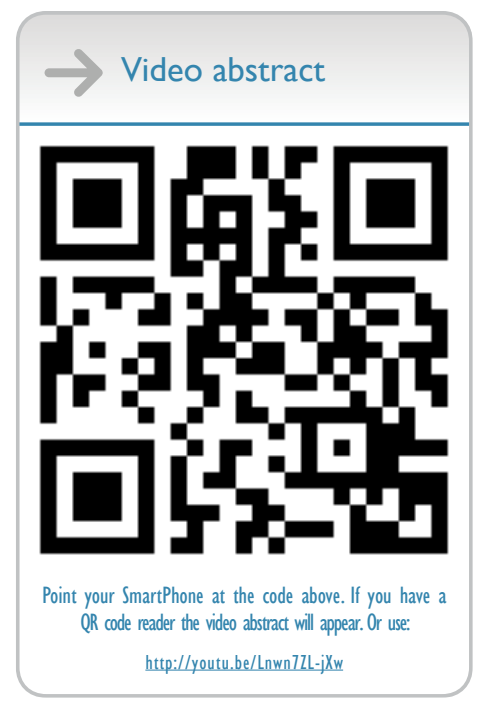

Correspondence: Shahira F El-Menshawe Department of Pharmaceutics and Industrial Pharmacy, Faculty of Pharmacy, Beni-Suef University, EL-Salam St, El-Maadi, Cairo II 728, Egypt

Tel +2001001916181

Email shahirafawzyelmenshawe@ yahoo.com
Purpose: Herbal supplements are currently available as a safer alternative to manage obesity, which has become a rising problem over the recent years. Many chemical drugs on the market are designed to prevent or manage obesity but high cost, low efficacy, and multiple side effects limit its use. Nano lipo-vesicles phytosomal thermogel of Soybean, Glycine max (L.) Merrill, was formulated and evaluated in an attempt to investigate its anti-obesity action on body weight gain, adipose tissue size, and lipid profile data.

Methods: Three different techniques were used to prepare phytosome formulations including solvent evaporation, cosolvency, and salting out. The optimized phytosome formulation was then selected using Design Expert ${ }^{\circledR}$ (version 7.0.0) depending on the highest entrapment efficiency, minimum particle size (PS), and maximum drug release within 2 hours as responses for further evaluation. The successful phytosome complex formation was investigated by means of Fourier-transform infrared spectroscopy and determination of PS and zeta potential. Phytosome vesicles' shape was evaluated using transmission electron microscope to ensure its spherical shape. After characterization of the optimized phytosome formulation, it was incorporated into a thermogel formulation. The obtained phytosomal thermogel formulation was evaluated for its clarity, homogeneity, $\mathrm{pH}$, and gel transformation temperature besides rheology behavior and permeation study. An in vivo study was done to investigate the anti-weight-gain effect of soy phytosomal thermogel.

Results: EE was found to be $>99 \%$ for all formulations, PS ranging from 51.66-650.67 while drug release was found to be (77.61-99.78) in range. FTIR and TEM results confirmed the formation of phytosome complex. In vivo study showed a marked reduction in body weight, adipose tissue weight and lipid profile.

Conclusion: Concisely, soy phytosomal thermogel was found to have a local anti-obesity effect on the abdomen of experimental male albino rats with a slight systemic effect on the lipid profile data.

Keywords: soy, Glycine max, lipase, phytosomal thermogel, topical delivery, natural treatment

\section{Introduction}

Obesity is a common health problem around the world that impacts human general health and social life and may affect vital organs such as heart, kidney, and liver. ${ }^{1}$ Several chemical anti-obesity drugs were withdrawn from the market because of their serious side effects, and so there is a great interest now toward herbal remedies as an alternative for treatment of obesity. 
Many experimental trials were done to evaluate the anti-obesity effect of different herbal products, for example, Dioscorea nipponica was found to have anti-obesity effect upon administration as an oral emulsion, ${ }^{2}$ Gambi-hwan extract was able to prevent weight gain after 10 weeks of oral administration, ${ }^{3}$ and also Clerodendron glandulosum aqueous extract gave positive results in weight gain control when mixed with the diet of the experimental animals. ${ }^{4}$

Recently, the topical route has received considerable attention as it is a noninvasive route and has a high bioavailability level as it delivers the drug directly to the site of action avoiding first-pass effect of liver and gastrointestinal tract-related problems. ${ }^{5}$ Most of the phytoconstituents are highly water-soluble substances such as saponins and flavonoids, and thus have a poor lipid solubility that came besides their large molecular weight, which became the reason for their very poor absorption and consequently bioavailability especially in case of transdermal administration route. ${ }^{6}$ However, topical administration of capsaicin, a major constituent of chillies, was found to have local anti-obesity effect, ${ }^{7}$ as well as glycyrrhetinic acid, the active principle component of licorice that showed significant reduction of subcutaneous thigh fat thickness when administered topically. ${ }^{8}$

Many approaches were developed to overcome the obstacle of poor absorption of the herbal products, and an important one of those approaches is phytosome complex formation. Phytosome is a complex, produced by forming a hydrogen bond between stoichiometric amounts of herbal extract functionalities and phospholipid polar heads using a suitable solvent to give nanosized vesicles with high bioavailability. Better stability of phytosomes over liposomes can be explained by the fact that liposome formation can be obtained by just mixing a water-soluble substance with phospholipids with no chemical bond formation. ${ }^{9}$

Thermogel, a gel that changes in viscosity according to temperature change, is considered an important formulation that enhances the topical transdermal delivery of many drugs. ${ }^{10}$

Soybean, Glycine $\max ($ L.) Merrill family Fabaceae, was known to have a significant effect on body weight control because of its content of saponin, ${ }^{11}$ protein, ${ }^{12}$ and phosphatidylcholine (PC). ${ }^{13}$ However, the mechanism is still unexplained. ${ }^{14}$

In this study, the effect of soy phytosomal thermogel in controlling high-fat diet (HFD)-induced weight gain was investigated in experimental albino rats.

\section{Materials and methods Materials}

Soybean, G. $\max ($ L.) Merrill family Fabaceae, was obtained from Haraz, Babb El-Khalk, Egypt, and kindly authenticated by Professor Dr Mohamed El-Gebaly, Taxonomy Specialist at ElOrman Botanical Garden, Giza, Egypt; methanol and acetonitrile (high-performance liquid chromatography [HPLC] grade; Cornell Lab, Cairo, Egypt); standard soy saponin B (Wako Pure Chemical Industries, Osaka, Japan); PC (Sigma-Aldrich Co., St Louis, MA, USA); methylparaben (EL-Gomhouria Co., Cairo, Egypt); polyethylene glycol (PEG 400), hydroxypropyl methylcellulose (HPMC) (E 50 LV), Pluronic F127 (Poloxamer407), propylparaben (LOBA Chemie, India); dimethyl sulfoxide (DMS), n-hexane, ethanol (ADWIC; El-Nasr Pharmaceutical Chemicals Co., Egypt); cellophane membrane (12,000-14,000 Dalton molecular weight; El-Maadi Co., Cairo, Egypt).

\section{Preparation of soy extract}

Soybean seeds were finely powdered to yield soy flour, then $100 \mathrm{~g}$ of soy flour was accurately weighed and soaked in $1 \mathrm{~L}$ of methanol at room temperature $\left(25^{\circ} \mathrm{C}\right)$ with continuous agitation for 24 hours using a magnetic stirrer (C-MAG HS 7 digital; IKA, Staufen, Germany). The obtained extract solution was filtered and methanol was evaporated using a rotary evaporator (IKA ${ }^{\circledR} \mathrm{RV} 10$ basic; IKA) at $30^{\circ} \mathrm{C}$ and $120 \mathrm{rpm}$. After complete solvent evaporation, the yielded dry extract was stored at $4{ }^{\circ} \mathrm{C}$ until further use..$^{15}$

Soy extract and standard soy saponin were analyzed using HPLC apparatus (Dionex Ultimate 3000, quaternary gradient HPLC [Berlin, Germany] with Smart line manager5000 degasser and Smart line pump-1000; Knauer, Germany) at $\lambda_{\text {max }}=205 \mathrm{~nm}$ (UV-detector). This method was adapted from Zhang J's report ${ }^{15}$ with slight modification.

Serial dilutions $(0.01-0.1 \mathrm{mg} / \mathrm{mL})$ of soy extract in both methanol and buffer solution ( $\mathrm{pH} 4$ ) were prepared. Samples were filtered using syringe filter $(0.25 \mu \mathrm{m}$ pore size; Sartorius, Gottingen, Germany), then chromatographed on Thermo Scientific ODS C18 RP column (1504.6, $5 \mathrm{~mm}$ ) in isocratic mode, and the temperature was set at $25^{\circ} \mathrm{C}$. Acetonitrile and deionized water $(80: 20 \mathrm{v} / \mathrm{v})$ mixture was used as an optimized degassed mobile phase at $1.5 \mathrm{~mL} / \mathrm{min}$ flow rate and with an injection volume of $50 \mu \mathrm{L}$. Standard calibration curve of the analyzed soy extract was established.

\section{Experimental design}

Three-level factorial design quadratic model was employed using Design Expert (version 7.0.0; Stat-Ease Inc., 
Minneapolis, MN, USA), to investigate the combined effect of three independent variables, $\mathrm{PC} \%(1 \%$ and $3 \%)$, extract $\%$ (1\% and 3\%), and method of preparation (solvent evaporation, cosolvency, and salting out), on three dependent variables, entrapment efficiency percentage (EE\%), particle size (PS), and percentage of drug released within 2 hours (Table 1).

\section{Preparation of soy phytosomes Solvent evaporation}

Dried soy extract and PC (according to the ratio clarified in Table 1) were dissolved into $10 \mathrm{~mL}$ of ethanol and refluxed for 2 hours under vacuum using rotary evaporator (IKA RV10 basic; IKA) at $30^{\circ} \mathrm{C}$ and $120 \mathrm{rpm}$. After complete evaporation of ethanol, the resulted residue was hydrated with distilled water to obtain the phytosomal suspension. ${ }^{16}$

\section{Cosolvency}

Two separate flasks each containing $10 \mathrm{~mL}$ of methanol were used to dissolve the dried soy extract and PC (according to the ratio clarified in Table 1); after that, the dissolved soy extract was added dropwise to the dissolved PC with stirring on a magnetic stirrer (C-MAG HS 7 digital; IKA) for 1 hour. ${ }^{16}$

\section{Salting out}

Ethanol $(10 \mathrm{~mL})$ was used to dissolve both dried soy extract and PC (according to the ratio clarified in Table 1) with continuous agitation on a magnetic stirrer (C-MAG HS 7 digital; IKA), then n-hexane was added dropwise to the resulted residue till complete precipitation of phytosome vesicles occurred. ${ }^{16}$

\section{Characterization of phytosomes}

\section{Entrapment efficiency}

Ultracentrifugation technique ${ }^{17}$ was used to determine the $\mathrm{EE} \%$ of the prepared soy phytosomes. Briefly, soy phytosome formulations were centrifuged at $4{ }^{\circ} \mathrm{C}$ and $15,000 \mathrm{rpm}$ for 90 minutes using cooling centrifuge apparatus (Sigma Laborzentrifugen D-37520, Osterode-am-Harz, Germany). The supernatant was separated and then analyzed using the same HPLC analysis method mentioned previously.

$\mathrm{EE} \%$ was calculated using the following equation:

$$
\mathrm{EE} \%=\frac{\mathrm{DT}-\mathrm{DS}}{\mathrm{DT}} \times 100
$$

where DT is the theoretical amount of soy extract while DS is the detected one.

\section{PS and polydispersity index (PDI)}

The PS and PDI were determined at $25^{\circ} \mathrm{C}$ by photon correlation spectroscopy using zeta seizer (Malvern ZetaSizer 3000; Malvern Instruments, Malvern, UK) at a fixed angle of $90^{\circ} .18$

\section{In vitro release}

Percentage of soy extract released within 2 hours from the prepared phytosome vesicles was determined using modified USP Dissolution Tester apparatus II method (Paddle typeErweka DT-720; Erweka GmbH, Heusenstamm, Germany). Briefly, cellophane membrane with a diffusion area of $4.9 \mathrm{~cm}^{2}$ was used as a diffusion membrane, cut out, stretched over two open edges of a glass tube, and tied well. Soy phytosome preparations were added into the cellophane-covered tubes, which were then fixed on the dissolution tester apparatus

Table I Design matrix depicting the experimental runs and values of the response variables obtained for experimental runs for soy-loaded phytosomes

\begin{tabular}{|c|c|c|c|c|c|c|}
\hline Run & $\begin{array}{l}\text { Factor I, } \\
\text { PC\% }\end{array}$ & $\begin{array}{l}\text { Factor } 2 \text {, } \\
\text { extract } \%\end{array}$ & $\begin{array}{l}\text { Factor 3, } \\
\text { method }\end{array}$ & $\begin{array}{l}\text { Response I, } \\
\text { EE (\%) }\end{array}$ & $\begin{array}{l}\text { Response 2, } \\
\text { PS (nm) }\end{array}$ & $\begin{array}{l}\text { Response } 3 \text {, } \\
\text { R (\% within } 2 \text { hours) }\end{array}$ \\
\hline I & 3.00 & 1.00 & Evaporation & 99.9297 & 650.67 & 81.99 \\
\hline 2 & 1.00 & 3.00 & Evaporation & 99.8494 & 182.96 & 83.18 \\
\hline 3 & 3.00 & 3.00 & Evaporation & 99.9900 & 667.24 & 85.67 \\
\hline 4 & 1.00 & 1.00 & Evaporation & 99.7388 & 51.660 & 77.61 \\
\hline 5 & 3.00 & 3.00 & Cosolvency & 99.9638 & 369.56 & 99.78 \\
\hline 6 & 1.00 & 3.00 & Cosolvency & 99.9047 & 81.060 & 82.32 \\
\hline 7 & 3.00 & 1.00 & Cosolvency & 99.9125 & 285.33 & 81.15 \\
\hline 8 & 1.00 & 1.00 & Cosolvency & 99.8917 & 63.100 & 78.86 \\
\hline 9 & 3.00 & 1.00 & Salting & 99.8582 & 422.58 & 79.75 \\
\hline 10 & 1.00 & 3.00 & Salting & 99.8270 & 282.60 & 83.85 \\
\hline 11 & 3.00 & 3.00 & Salting & 99.9716 & 466.06 & 92.43 \\
\hline 12 & 1.00 & 1.00 & Salting & 99.7934 & 281.86 & 79.57 \\
\hline
\end{tabular}

Abbreviations: EE, entrapment efficiency; PC, phosphatidylcholine; PS, particle size; R, drug release percentage. 
replacing its paddles. The speed of the dissolution apparatus was set at $100 \mathrm{rpm}$ and the temperature was maintained at $32^{\circ} \mathrm{C} \pm 0.5^{\circ} \mathrm{C}$, while the release medium was $500 \mathrm{~mL}$ of phosphate buffer $(\mathrm{pH} 4)$. Samples were withdrawn from the release medium at predetermined time intervals $(5,10,15$, 30,60 , and 120 minutes) and immediately replaced by an equal volume of fresh phosphate buffer $(\mathrm{pH} 4)$, and then they were analyzed using the same HPLC method mentioned earlier. ${ }^{19}$

\section{Zeta potential}

The charge of the diluted phytosome vesicles of the optimized formulation was determined by light scattering technique using zeta sizer (Malvern ZetaSizer 3000; Malvern Instruments). ${ }^{18}$

Fourier-transform infrared (FTIR) spectroscopy study FTIR spectroscopy study was done to the optimized phytosome formulation and then compared with that of soy extract and PC using an FTIR spectrophotometer (Brukeralpha; Specac, Ettingen, Germany). Briefly, $0.5 \mathrm{~mL}$ of the sample was placed just below the fixed probe of the FTIR spectrophotometer and scanned over the 3,500-1,000 $\mathrm{cm}^{-1}$ wavenumber region. ${ }^{20}$

\section{Morphology}

Successful phytosome vesicles formation was confirmed by high-resolution transmission electron microscopy (HRTEM) (Technai G2 Spirit Twin; Okolab, Naples, Italy) after dilution of the optimized phytosome formulation with $5 \mathrm{~mL}$ distilled water, and a drop of it being withdrawn and placed over a carbon-coated copper grid at an accelerating voltage of $120 \mathrm{kV}$, which was captured by Veleta camera. $^{21}$

\section{Preparation of phytosomal thermogel}

Thermogel was prepared according to the cold method. ${ }^{22}$ Briefly, on a magnetic stirrer (C-MAG HS 7 digital; IKA), HPMC 3\% w/v was slowly added to the phosphate buffer $(0.1 \mathrm{M}, \mathrm{pH} 4)$ at $4^{\circ} \mathrm{C}$ with gentle mixing. Methylparaben $(0.02 \% \mathrm{w} / \mathrm{v})$ and propylparaben $(0.02 \% \mathrm{w} / \mathrm{v})$ as preservatives, PEG400 (4\% w/v) as a humectant, and DMS and ethanol as penetration enhancers $(2 \% \mathrm{w} / \mathrm{v})$ were then added to the polymer solution as well as Pluronic F127 (18\% w/v) that acted as a gel-transition polymer. Optimized soy phytosome formulation was then added dropwise to the prepared thermogel with stirring on a magnetic stirrer (C-MAG HS 7 digital; IKA) at $4^{\circ} \mathrm{C}$ to obtain soy phytosomal thermogel that was allowed to dissolve overnight at $4^{\circ} \mathrm{C} .{ }^{23}$
Characterization of phytosomal thermogel Clarity, homogeneity, and $\mathrm{pH}$

Phytosomal thermogel was evaluated for its clarity and homogeneity by visual inspection while $\mathrm{pH}$ was determined using pH-meter (Jenway 3510 pH meter; Staffordshire, UK).

\section{Gel transformation temperature}

Gel transformation temperature was determined using modified "Tilting tube method". ${ }^{24}$ Briefly, $2 \mathrm{~mL}$ of the prepared soy phytosomal thermogel was transferred to a test tube and then tilted into a thermostatic water bath (Memmert, Schwabach, Germany) at $90^{\circ}$ angle with gradual raising of the water bath temperature. The temperature at which the formulation showed no flow upon tilting was recorded.

\section{Rheology study}

Soy phytosomal thermogel rheology behavior was investigated over a wide range of speed (10-100 rpm) and at different temperatures $\left(-4^{\circ} \mathrm{C}, 25^{\circ} \mathrm{C}\right.$, and $\left.32^{\circ} \mathrm{C}\right)$ using Brookfield viscometer (RV-TD; Brookfield Engineering Laboratories, Stoughton, MA, USA) with a suitable spindle (CP52 model $\mathrm{HB}$ ), and there was a 30-second time gap between every two successive measurements. ${ }^{25}$

\section{Permeation study}

Permeation profile of soy from the optimized phytosomal thermogel preparation was studied with and without addition of penetration enhancers (ethanol and DMS) using the USP Dissolution Tester method previously mentioned and with the same experimental conditions but using shaved abdominal area $\left(4.9 \mathrm{~cm}^{2}\right)$ of male albino rat skin instead of the cellophane membrane. ${ }^{26}$ Cumulative percentage of soy extract permeated was calculated using Fick's law:

$$
\mathrm{J}_{\mathrm{ss}}=\frac{\mathrm{dQ} / \mathrm{dt}}{\mathrm{A}}
$$

where $\mathrm{J}_{\mathrm{ss}}$ is the steady-state flux, $\mathrm{dQ} / \mathrm{dt}$ is the permeation rate, $\mathrm{Qt}$ is the cumulative amount of soy permeated at the time $(\mathrm{t})$, and $\mathrm{A}$ is the treated area $\left(4.9 \mathrm{~cm}^{2}\right)$.

The enhancement ratio (Er) that resulted from adding the penetration enhancers was calculated from the following equation:

$$
\mathrm{Er}=\frac{\begin{array}{l}
\mathrm{J}_{\mathrm{ss}} \text { of the phytosomal thermogel with } \\
\text { penetration enhancers }
\end{array}}{\begin{array}{l}
\mathrm{J}_{\text {ss }} \text { of the phytosomal thermogel without } \\
\text { penetration enhancers }
\end{array}}
$$




\section{In vivo study}

Twenty male albino rats $(225 \pm 5 \mathrm{~g})$ aged 6 weeks were obtained from the animal house of Nahda University BeniSuef, Egypt, and divided into four main groups $(n=5)$ as follows: Group 1, treated with plain thermogel; Group 2, treated with crude soy extract thermogel; Group 3, treated with $2.5 \%$ soy phytosomal thermogel; Group 4, untreated control group. All groups were housed in separate cages and were allowed to access $50 \%$ HFD (standard forage mixed with 3\% milk powder) and water ad libitum. The room temperature was maintained at $23^{\circ} \mathrm{C} \pm 2{ }^{\circ} \mathrm{C}$ and 12 hours light-and-dark cycle.

Experimental protocol was done according to the guidelines of Beni-Suef Animal House approved by Pharmacology and Toxicology Department, Faculty of Pharmacy, BeniSuef University, on 20 June 2009, which was based on the guidelines suggested by the recommendations of the National Institutes of Health Guide for Care and Use of Laboratory Animals (Publication No 85-23, revised 1985).

Rats were treated locally after hair removal of the treated abdominal skin area $\left(4.9 \mathrm{~cm}^{2}\right)$ with a razor. All preparations, according to each group, were administered topically to the rat's abdomen once daily for 1 month. ${ }^{8}$ Food intake amount of all rats was detected daily.

All rats were reweighed after 1 month of the treatment and the amount of weight gain and its percentage were calculated from the following equations:

Amount of weight gain

$=($ Body weight after one month - Body weight on day 1$)$

Weight change $\%$

$$
=\frac{\text { Amount of weight gain after one month }}{\text { Body weight on day } 1} \times 100 \%
$$

Blood samples were collected from the retro-orbital plexus vein and centrifuged at 3,000 rpm for 20 minutes. Supernatant serum was transferred to Eppendorf tubes and analyzed for lipid profile data and lipase enzyme inhibition. ${ }^{27}$

Rats were killed by cervical dislocation at the end of the experiment, and adipose tissue of the hairless treated abdominal area $\left(4.9 \mathrm{~cm}^{2}\right)$ of all rats was dissected, weighed, and fixed in $10 \%$ formalin/saline solution, ${ }^{28,29}$ then sectioned and embedded in paraffin, and after that it was stained with hematoxylin and eosin for histological evaluation $($ magnification $\times 100) .7,30$

\section{Statistical analysis}

The significance of differences was established by two-way analysis of variance using Graph Pad Prism version 6.0 for Windows, Graph Pad Software (San Diego, CA, USA). The results were expressed as mean $\pm \mathrm{SD}$ and $P$-value $<0.0001$ was considered statistically significant.

\section{Results}

\section{Standard calibration curve of soy extract}

Saponin extract exhibited identical bands to those of the reference soy saponin in HPLC chromatogram. According to Beer-Lambert law, Figure 1 showed the standard calibration curves of soy extract in methanol and buffer solution ( $\mathrm{pH} 4)$, and both curves showed a linear relationship between the soy extract concentration and area under the curve over a concentration range of $0.01-0.08 \mathrm{mg} / \mathrm{mL}$. The regression equations were found to be $(\mathrm{y}=10.58 \mathrm{x}+0.192)$ with $\left(R^{2}=0.9731\right)$ and $(\mathrm{y}=0.172 \mathrm{x}-0.358)$ with $\left(R^{2}=0.961\right)$ for methanol and buffer solution (pH 4), respectively.

\section{Optimization data analysis and validation of optimization model}

The coefficient of determination $\left(R^{2}\right)$, adjusted $R^{2}$, predicted $R^{2}$, and percentage coefficient of variation values were used to evaluate the fitness of the quadratic model to the experimental data (Table 2). The response surface analysis was carried out on three-dimensional (3D) response surface

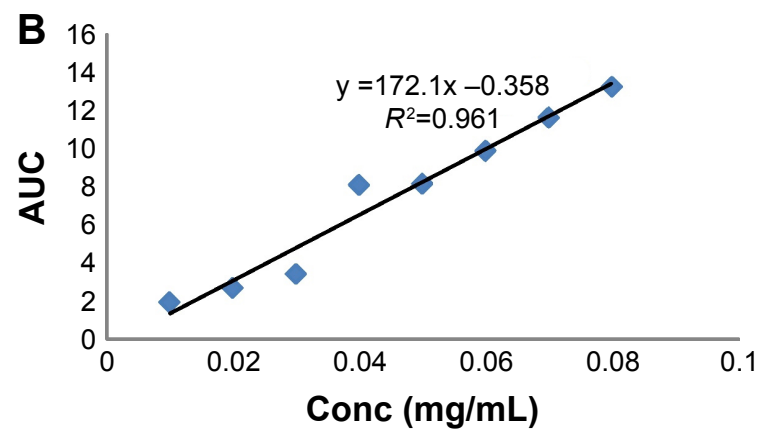

Figure I Standard calibration curve of soy extract in methanol (A) and buffer solution, $\mathrm{pH}=4$ (B). Abbreviation: AUC, area under the curve. 
Table 2 Summary of results of regression analysis of responses

\begin{tabular}{llllllr}
\hline Response & $\boldsymbol{R}^{2}$ & Adjusted $\boldsymbol{R}^{2}$ & $\begin{array}{l}\text { Adequate } \\
\text { precision }^{\mathbf{a}}\end{array}$ & $\begin{array}{l}\text { Model } \\
\text { F-value }^{\mathrm{b}}\end{array}$ & ${\text { Predicted } \boldsymbol{R}^{2}}^{\mathbf{C V}^{\mathrm{c}}}$ \\
\hline EE (\%) & 0.8085 & 0.6991 & 8.312 & 7.39 & 0.4372 & 0.042 \\
PS (nm) & 0.8248 & 0.7248 & 7.859 & 8.24 & 0.4853 & 34.64 \\
$R(\%$ within 2 hours) & 0.7267 & 0.5705 & 6.466 & 4.65 & 0.1968 & 4.960 \\
\hline
\end{tabular}

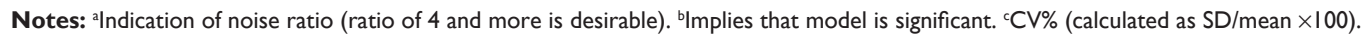

Abbreviations: CV\%, percentage coefficient of variation; $\mathrm{EE}$, entrapment efficiency; PS, particle size; $R$, drug release percentage.

plots and 2D contour plots in order to understand the interaction if present (Figure 2A-C). The fitted models could be viewed as regression equations $(6,7$, and 8$)$ generated by the software (Design Expert version 7.0.0; Stat-Ease Inc.), and the possible experimental solutions obtained from the numerical optimization with desirability values are illustrated in Table 3.

$$
\begin{aligned}
\mathrm{EE}= & +99.89+0.052 \mathrm{~A}+0.032 \mathrm{~B}-8.925 \mathrm{E} \\
& \quad-003 \mathrm{C}[1]-0.023 \mathrm{C}[2] \\
\mathrm{PS}= & +317.06+159.85 \mathrm{~A}+24.52 \mathrm{~B}+71.08 \mathrm{C}[1] \\
& +46.22 \mathrm{C}[2]
\end{aligned}
$$

A

Evaporation
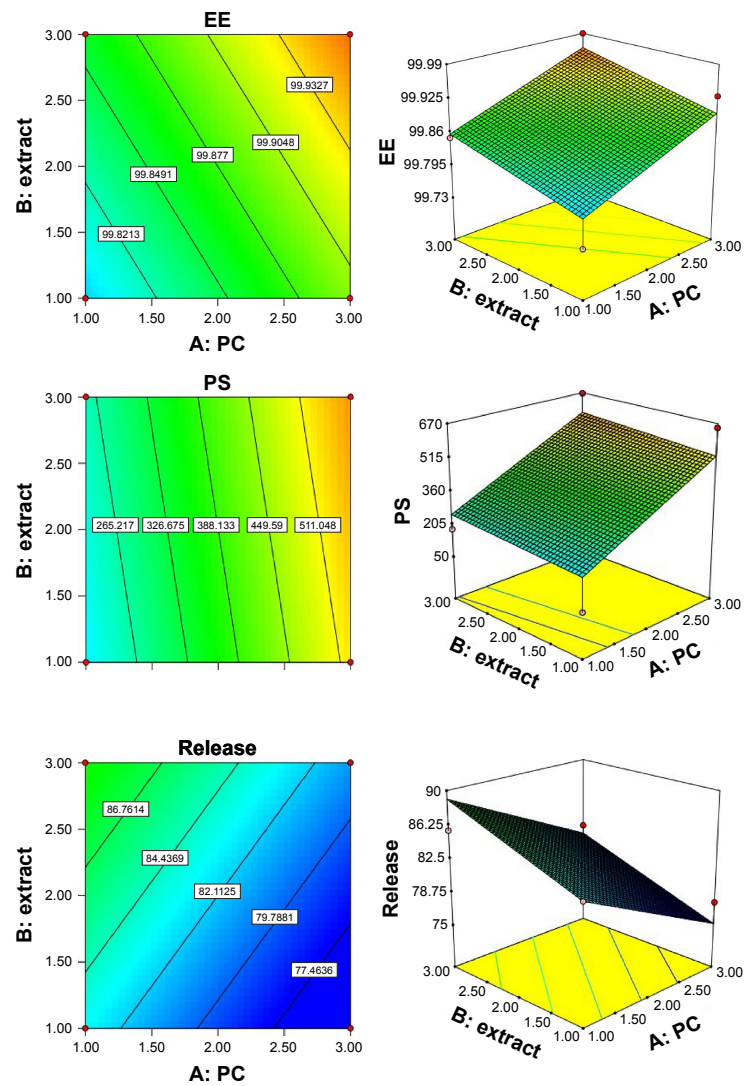

$$
R=+83.85-4.03 \mathrm{~A}+2.95 \mathrm{~B}-1.73 \mathrm{C}[1]+0.053 \mathrm{C}[2]
$$

\section{Evaluation of phytosome preparations Entrapment efficiency}

Perfect loading of soy on the phytosome nanoparticles and minimal loss of it throughout the preparation steps were easily reflected in the high EE\% as clarified in Table 1.

\section{Particle size and PDI}

Mean of the PS $(n=3)$ of all phytosome formulations was found to be in the range of 51.66-667.24 nm. PDI of the optimized formulation was found to be 0.11 , which indicates a homogeneous vesicle size distribution as small values of

B Cosolvency
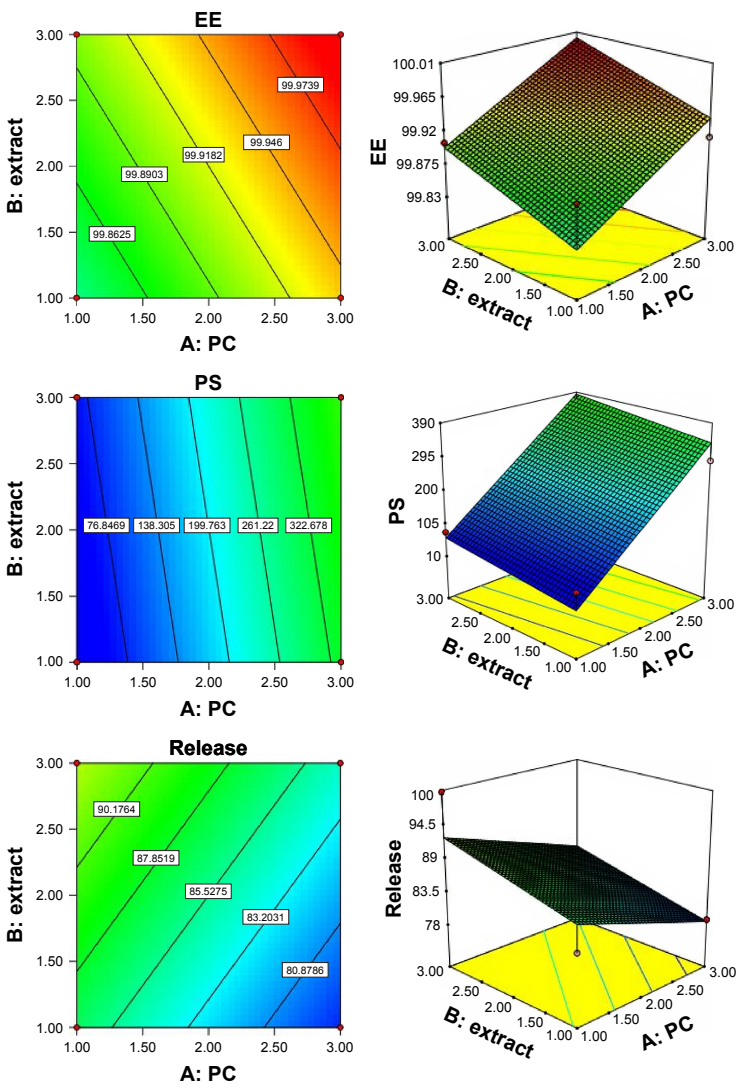

Figure 2 (Continued) 


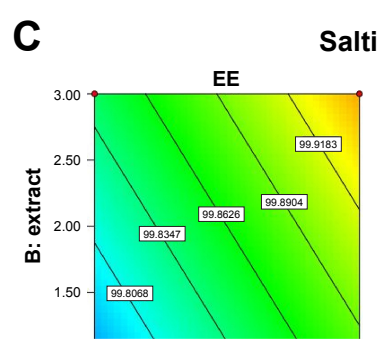

Salting out
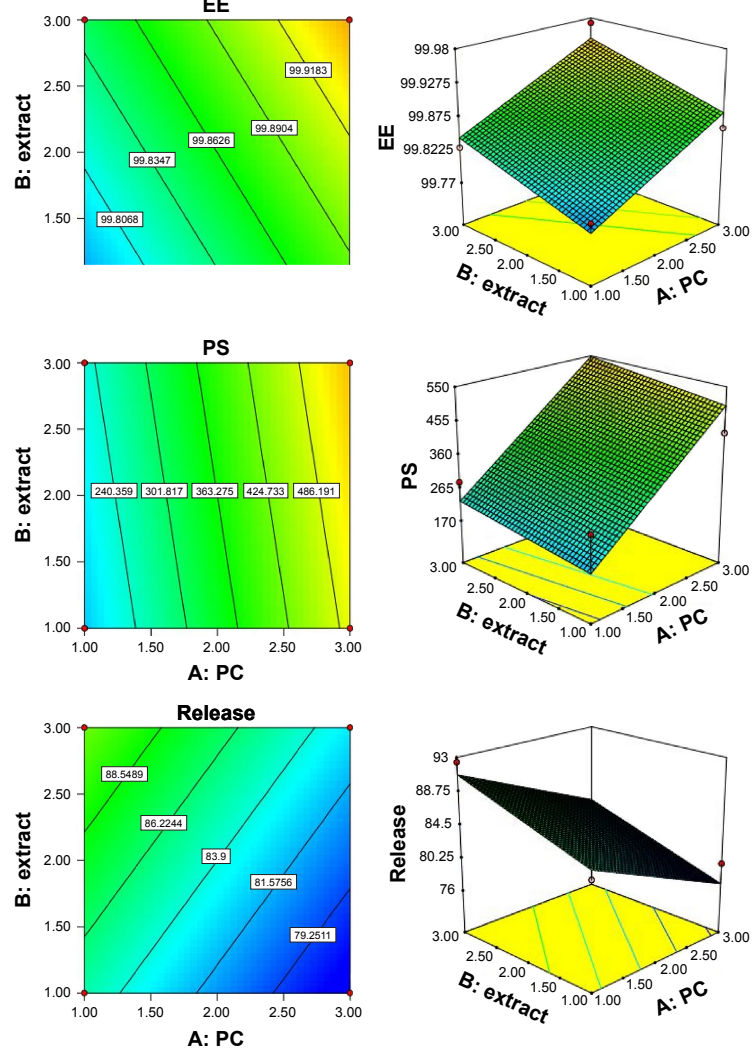

Figure 2 Response surface and contour plots showing the influence of phospholipid (PC) and extract of soy loaded phytosomes on different responses using solvent evaporation method $(\mathbf{A})$, co-solvency method $(\mathbf{B})$ and salting out method (C).

Abbreviation: $\mathrm{EE}$, entrapment efficiency.

PDI $(<0.1)$ indicate a homogeneous population, while PDI values $(>0.4)$ are more heterogenic. ${ }^{31}$

\section{Drug release}

Release profile of all soy phytosome formulations showed a great enhancement in the released percentage within 2 hours in comparison with the crude soy extract $(77.16 \%$ within 2 hours) (Table 1). ${ }^{32}$

\section{Zeta potential}

Phytosome stability was confirmed when zeta potential value was $> \pm 30 \mathrm{Mv}$, so optimized phytosome formulation $(-51 \pm 7.06 \mathrm{mV})$ can be considered highly stable. ${ }^{33}$

\section{FTIR}

FTIR spectra (Figure 3) confirmed the formation of phytosome vesicles by comparing the spectra of the prepared

Table 3 Results of numeric optimization for soy-loaded phytosomes

\begin{tabular}{|c|c|c|c|c|c|c|}
\hline \multicolumn{2}{|l|}{ Name } & Goal & \multicolumn{2}{|l|}{ Lower limit } & Upper limit & \multirow{2}{*}{$\begin{array}{l}\text { Importance } \\
3\end{array}$} \\
\hline PC & & Minimize & \multicolumn{2}{|l|}{ I } & 3 & \\
\hline Extract & & Maximize & \multicolumn{2}{|l|}{ I } & 3 & 3 \\
\hline Method & & Is in range & \multicolumn{2}{|l|}{ Evaporation } & Cosolvency & 3 \\
\hline $\mathrm{EE}$ & & Maximize & \multicolumn{2}{|l|}{99.7388} & 99.99 & 3 \\
\hline PS & & Minimize & \multicolumn{2}{|l|}{51.66} & 667.24 & 3 \\
\hline$R$ & & Maximize & 77.61 & & 99.78 & 3 \\
\hline \multicolumn{3}{|c|}{ Phytosome } & \multicolumn{3}{|l|}{ Response } & \multirow[t]{2}{*}{ Desirability } \\
\hline PC & Ext & Method & EE & PS & $\boldsymbol{R}$ & \\
\hline 1.00 & 3.00 & Cosolvency & 99.8983 & 64.436 & 92.5008 & 0.840 \\
\hline 1.00 & 2.96 & Cosolvency & 99.897। & 63.4962 & 92.3876 & 0.834 \\
\hline 1.00 & 3.00 & Salting & 99.8427 & 227.948 & 90.8733 & 0.707 \\
\hline 1.00 & 3.00 & Evaporation & 99.8571 & 252.806 & 89.0858 & 0.697 \\
\hline 1.00 & 2.99 & Evaporation & 99.8567 & 252.547 & 89.0546 & 0.695 \\
\hline 1.19 & 3.00 & Evaporation & 99.8667 & 282.447 & 88.3395 & 0.675 \\
\hline
\end{tabular}

Abbreviations: EE, entrapment efficiency; Ext, soy extract; PC, phosphatidylcholine; PS, particle size; $R$, drug release percentage. 

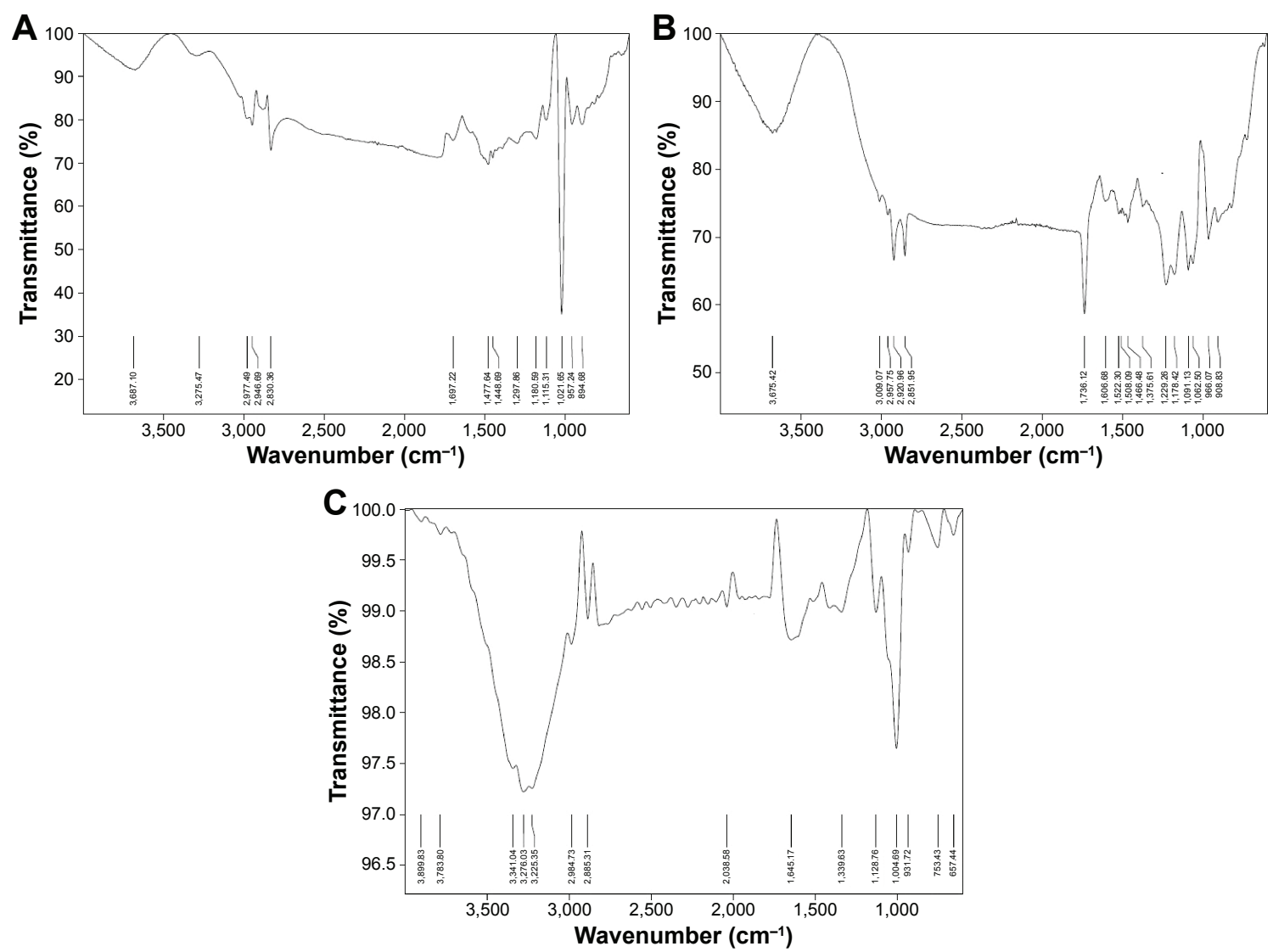

Figure 3 Fourier-transform infrared spectra of the optimized soy phytosome formulation (A) in comparison with that of phosphatidylcholine (B) and soy extract (C).

phytosome with that of PC and soy extract as the difference between them in fingerprint region (below $1,500 \mathrm{~cm}^{-1}$ ) indicates the new phytosome complex formation. The band at $3,276 \mathrm{~cm}^{-1}$ was attributed to the stretching vibration of the phenolic-OH group in natural soy. Moreover, sharp absorption bands were observed at $1,645 \mathrm{~cm}^{-1}$ ( $\mathrm{C}=\mathrm{O}$ vibration) and $1,004 \mathrm{~cm}^{-1}$ (aromatic $\mathrm{C}-\mathrm{O}$ stretching vibration). In $\mathrm{PC}$, the strong peaks at 1,736 and $1,229 \mathrm{~cm}^{-1}$ were due to $\mathrm{C}=\mathrm{O}$ absorption and $\mathrm{P}=\mathrm{O}$ absorption, respectively.

The strong peaks at 2,920 and 2,851 $\mathrm{cm}^{-1}$ and the weak peak at $1,375 \mathrm{~cm}^{-1}$ in PC could be due to stretching and
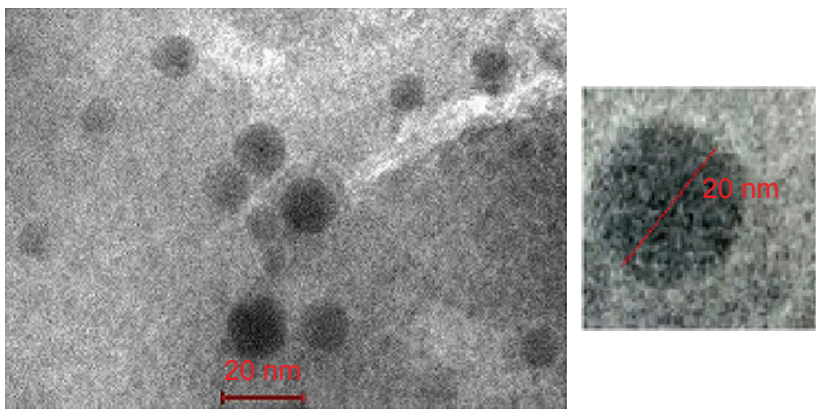

Figure 4 Transmission electron microscope photograph of soy phytosomeoptimized formulation. deformation of methyl groups. The peak at $1,466 \mathrm{~cm}^{-1}$ observed could be due to bending vibration of $\mathrm{CH}_{2}$, while $3,009 \mathrm{~cm}^{-1}$ was for $\mathrm{C}=\underline{\mathrm{C}}-\mathrm{H}$ and $2,957 \mathrm{~cm}^{-1}$ was for $\mathrm{C}-\underline{\mathrm{C}-\mathrm{H}}$ in PC. A shift from $3,675 \mathrm{~cm}^{-1}$ of PC to $3,687 \mathrm{~cm}^{-1}$ compared with natural soy, $3,276 \mathrm{~cm}^{-1}$, was exhibited by phytosome complex besides $\mathrm{C}-\underline{\mathrm{C}-\mathrm{H}}$ that appears at $2,977 \mathrm{~cm}^{-1}$ for phytosome, $2,957 \mathrm{~cm}^{-1}$ for $\mathrm{PC}$, and $2,984 \mathrm{~cm}^{-1}$ for soy. These changes indicated that soy and PC formed the phytosome complex by hydrogen bond formation between

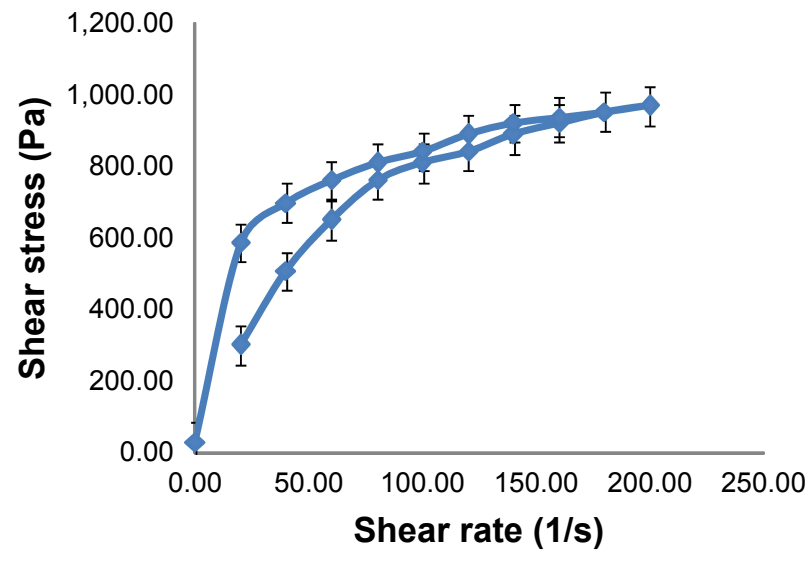

Figure $\mathbf{5}$ Rheology behavior of soy phytosomal thermogel. 


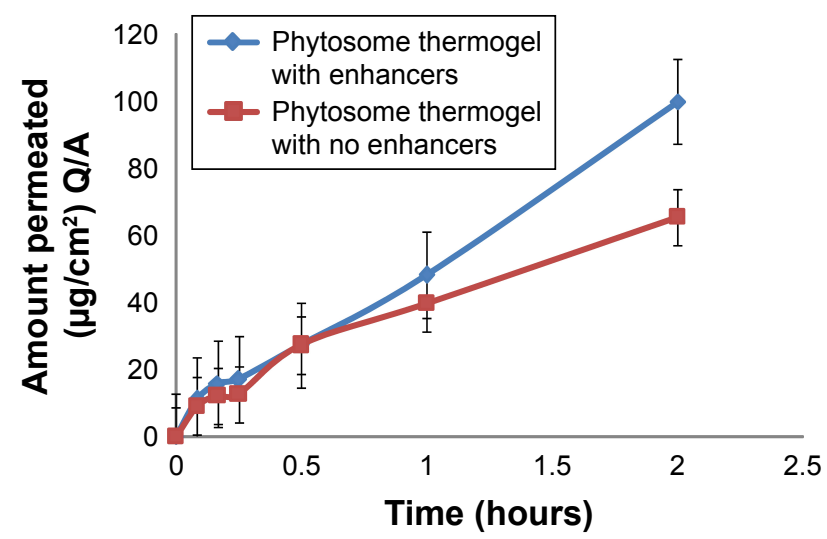

Figure 6 Permeation profile of soy phytosomal thermogel with and without using penetration enhancers.

Abbreviation: $\mathrm{Q} / \mathrm{A}$, quantity permeated through a specific skin area $\mathrm{A}$.

the $\mathrm{OH}$ group of soy phenol group and the $\mathrm{P}=\mathrm{O}$ group of the $\mathrm{PC} .{ }^{34,19}$

\section{Morphology}

Transmission electron micrograph showed spherical, selfclosed, rough surface vesicles with no indication of particle aggregation (Figure 4$){ }^{21}$

\section{Evaluation of phytosomal thermogel Clarity, homogeneity, and $\mathrm{pH}$}

Soy phytosomal thermogel was found to be clear, translucent, and homogeneous with a $\mathrm{pH}=4$, so safe skin application was assured with no expectation of any skin irritation or discomfort upon application. ${ }^{35}$

\section{Gel transformation temperature}

Gel transformation temperature of soy phytosomal thermogel was found to be $31.5^{\circ} \mathrm{C}$, which is suitable for skin delivery. ${ }^{35}$

\section{Rheology study}

Soy phytosomal thermogel showed a thixotropic behavior, which is an important property for thermogel preparations, which means a decrease in viscosity and shear stress with increasing shear rate and vice versa (Figure 5). ${ }^{25}$

\section{Permeation study}

Permeation flux of soy extract from the phytosomal thermogel was found to be 9.7309 and $5.2062 \mu \mathrm{g} / \mathrm{cm}^{2} \cdot \mathrm{h}$ with and without the addition of penetration enhancers, respectively, with $r^{2}=0.99$ for both and $\mathrm{Er}=1.8690$, which indicates the positive effect of penetration enhancers on the permeation profile of soy (Figure 6). ${ }^{26}$

\section{In vivo study}

Soy phytosomal thermogel-treated rats group showed a marked decrease in body weight, adipose tissue weight, and food consumption than the other treated rat groups and the control group (Table 4). ${ }^{2}$

Moreover, from the lipid profile data illustrated in Figure 7 and Table 5, it was observed that there was a significant decrease in total cholesterol, triglycerides, low-density lipoprotein cholesterol, and very low-density lipoprotein cholesterol, which can be attributed to a slight systemic action of soy phytosomal thermogel in comparison with the control-treated group. ${ }^{2}$

The histological analysis of epididymal adipose tissue (Figure 8) showed a decrease in the size of adipose cells in comparison with the control and crude soy thermogel groups and revealed the enhancement effect of phytosomal thermogel formulation on soy anti-obesity effect. ${ }^{2}$

\section{Discussion}

Soy was approved by many researchers to have an antiobesity effect because of its saponin, ${ }^{11}$ protein, ${ }^{12}$ and $\mathrm{PC}^{13}$ content, so in this study, this anti-obesity action was investigated topically.

Soy was extracted by continuous agitation method at $24^{\circ} \mathrm{C},{ }^{15}$ then 12 soy phytosome formulations were prepared with three different techniques and characterized to optimize one formulation with the highest $\mathrm{EE} \%$, minimum

Table 4 Effect of soy extract phytosomal thermogel on the body weight, adipose tissue weight, and food consumption of rats after I month of treatment

\begin{tabular}{lllll}
\hline & $\begin{array}{l}\text { Plain thermogel } \\
\text { group (GpI) }\end{array}$ & $\begin{array}{l}\text { Soy extract thermogel } \\
\text { group (Gp2) }\end{array}$ & $\begin{array}{l}\text { Soy extract phytosomal } \\
\text { thermogel group (Gp3) }\end{array}$ & $\begin{array}{l}\text { Control } \\
\text { group (Gp4) }\end{array}$ \\
\hline Initial body weight $(\mathrm{g})$ & $225.04 \pm 4.36$ & $225.84 \pm 3.16$ & $225.13 \pm 3.43$ & $225.8 \mathrm{I} \pm 3.75$ \\
Body weight after I month $(\mathrm{g})$ & $330.47 \pm 4.88$ & $310.86 \pm 7.15$ & $280.38 \pm 5.21$ & $340.88 \pm 5.11$ \\
Body weight gain amount $(\mathrm{g})$ & $105.43 \pm 6.06^{\mathrm{a}}$ & $85.030 \pm 6.43^{\mathrm{a}}$ & $55.260 \pm 6.94^{\mathrm{a}}$ & $115.07 \pm 8.83$ \\
Body weight gain percentage & $46.890 \pm 3.34^{\mathrm{a}}$ & $37.660 \pm 2.92^{\mathrm{a}}$ & $24.570 \pm 3.35^{\mathrm{a}}$ & $51.020 \pm 4.78$ \\
Weight of adipose tissue $(\mathrm{g})$ & $3.7810 \pm 0.98$ & $3.5210 \pm 0.79$ & $2.5510 \pm 0.66$ & $4.1670 \pm 0.58$ \\
Average daily food consumption (g/day) & $16.122 \pm 0.85$ & $14.476 \pm 0.83$ & $9.3840 \pm 0.46$ & $16.374 \pm 0.61$ \\
\hline
\end{tabular}

Notes: Values were expressed as mean $\pm \mathrm{SE}, \mathrm{n}=5$. ${ }^{\mathrm{H}} \mathrm{Has}$ a significant difference at $P<0.000 \mathrm{I}$, when compared with model control (Group IV) values. 


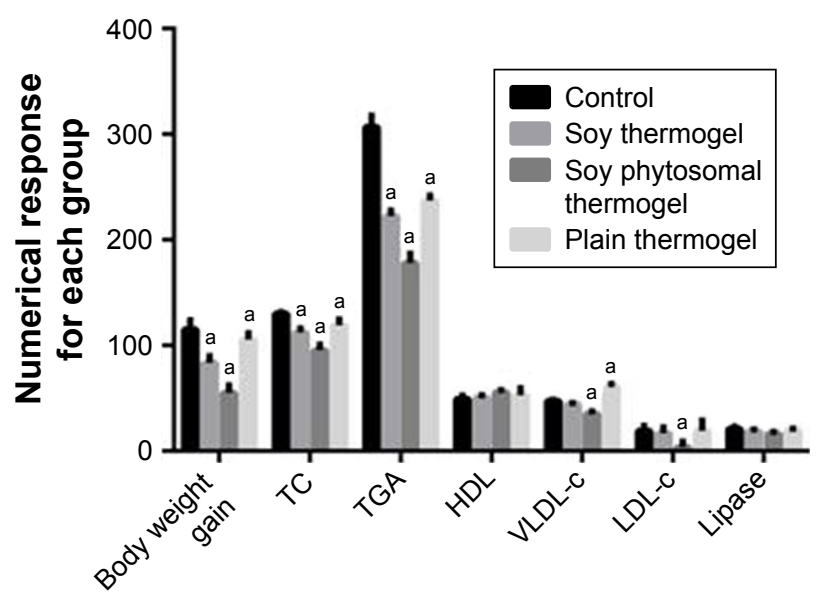

Figure 7 Two-way analysis of variance of body weight gain and lipid profile analysis for each animal group.

Note: ${ }^{a} \mathrm{H}$ as a significant difference at $P<0.000 \mathrm{I}$, when compared with model control (Group IV) values.

Abbreviations: HDL, high-density lipoprotein; LDL-c, low-density lipoprotein cholesterol; TC, total cholesterol; TGA, triglycerides; VLDL-c, very low-density lipoprotein cholesterol.

PS, and maximum release percentage within 2 hours as independent factors using Design Expert version 7.0.0 (Stat-Ease Inc.).

Regression equations for each response were produced by the model design (Eqs 6-8), and a positive factor in polynomial equations means that increasing the factor causes increase in the response while negative sign represents that increasing the factor decreases the response. These equations showed that both $\mathrm{PC} \%$ and soy extract $\%$ have a positive effect on both EE\% and PS, and this may be because soy extract also contains PC and it enhances its effect, and by increasing solid lipids percentage, the aggregation facilitated and leads to increasing the PS. ${ }^{36}$

High EE\% of phytosome formulations ( $>99 \%$ ) was expected because of the hydrogen bond formation between soy extract and PC. ${ }^{7}$ PS obtained is good for enhancement of $\mathrm{EE} \%,{ }^{37}$ release profile, and skin permeation. ${ }^{23}$ Soy extract $\%$ was found to have a positive effect on the release response within 2 hours. On the other hand, PC factor was found to have a negative effect on it, which may be due to that increasing PC increases the bond strength between the extract and the $\mathrm{PC}$ in phytosome, which may delay the release of soy. The 3D response surface and $2 \mathrm{D}$ contour plots were obtained by varying magnitudes of PC and soy extract $\%$, keeping the method of preparation constant, and results showed a significant effect of these factors on EE\%, PS, and drug release\% (Figure 2).

The optimized phytosome formulation was found to be the one prepared using cosolvency method with a $\mathrm{PC}=1 \%$ and extract $=3 \%$ (Table 2), which was then evaluated for zeta potential using TEM and FTIR. Zeta potential was found to be $-51 \mathrm{mV}$, and shifting in zeta potential value toward negative value can be attributed to the incorporation of soy into the phytosome and it indicates a high repulsion force between vesicles that prevents its aggregation and consequently gives a high stability for the phytosome suspension with high skin penetration ability. ${ }^{18}$

Soy phytosomal thermogel formulation was prepared and evaluated, and it was found to be clear, homogeneous, with $\mathrm{pH}$ value $=5.5$ and gel transformation temperature $=31.5^{\circ} \mathrm{C}$, which matches the required characteristics for skin delivery. Rheology study showed thixotropic behavior, which is a very important property for semisolid topical preparations as it gives indication of the physical and chemical changes occurred. ${ }^{25}$

In vivo study of soy phytosomal thermogel showed a marked decrease in the body weight gain, adipose tissue weight, food consumption, and the size of adipose cells for treated groups. Body weight gain amounts are $85.030 \pm 6.43 \mathrm{~g}$ in soy thermogel and 55.260 $\pm 6.94 \mathrm{~g}$ in soy phytosomal thermogel. This trend can be caused by the effect of different soy extract components that were approved to have anti-obesity effect including triglyceride soy saponin, which was investigated by Kim et al to have anti-obesity effect in vitro, ${ }^{11}$ and soy protein oral consumption showed anti-obesity effect as reported by Velasquez and Bhathena ${ }^{12}$ besides soy PC that was approved by Lee et al to have valuable effect on obesity. ${ }^{13}$

Table 5 Effect of soy extract phytosomal thermogel on the blood parameters in rats after I month of treatment

\begin{tabular}{|c|c|c|c|c|c|c|c|}
\hline Groups & $\begin{array}{l}\text { TC } \\
(\mathrm{mg} / \mathrm{dL})\end{array}$ & $\begin{array}{l}\text { TGA } \\
(\mathrm{mg} / \mathrm{dL})\end{array}$ & $\begin{array}{l}\text { HDL } \\
(\mathrm{mg} / \mathrm{dL})\end{array}$ & $\begin{array}{l}\text { LDL-c (Friedewald) } \\
(\mathrm{mg} / \mathrm{dL})\end{array}$ & $\begin{array}{l}\text { LDL-c (Iranian) } \\
\text { (mg/dL) }\end{array}$ & $\begin{array}{l}\text { VLDL-c } \\
\text { (mg/dL) }\end{array}$ & $\begin{array}{l}\text { Lipase } \\
(\mathrm{mg} / \mathrm{dL})\end{array}$ \\
\hline 1 & I I $9.24 \pm 5.49^{\mathrm{a}}$ & $237.19 \pm 4.61^{a}$ & $52.80 \pm 6.57$ & $19.00 \pm 9.82$ & $139.04 \pm 10.55$ & $47.44 \pm 0.92$ & $19.99 \pm 1.01$ \\
\hline 2 & $\mid \mathrm{I} 2.2 \mathrm{I} \pm 3.82^{\mathrm{a}}$ & $222.38 \pm 5.45^{\mathrm{a}}$ & $50.92 \pm 1.90$ & $16.81 \pm 5.58$ & $127.05 \pm 4.740$ & $44.48 \pm 1.09$ & $18.99 \pm 1.59$ \\
\hline 3 & $95.340 \pm 5.49^{a}$ & $178.06 \pm 8.93^{\mathrm{a}}$ & $55.73 \pm 2.02$ & $3.990 \pm 4.98^{\mathrm{a}}$ & $85.160 \pm 5.180$ & $35.61 \pm 1.79^{a}$ & $16.41 \pm 1.67$ \\
\hline 4 & $130.06 \pm 1.55^{\mathrm{a}}$ & $306.75 \pm 10.9^{a}$ & $49.39 \pm 3.13$ & $19.31 \pm 4.43$ & $187.83 \pm 5.520$ & $61.35 \pm 2.17$ & $21.14 \pm 1.88$ \\
\hline
\end{tabular}

Notes: Values were expressed as mean $\pm \mathrm{SE}, \mathrm{n}=5$. ${ }^{\mathrm{H}} \mathrm{Has}$ a significant difference at $P<0.000 \mathrm{I}$, when compared with model control (Group IV) values Group I, treated with plain thermogel; Group 2, treated with crude soy extract thermogel; Group 3, treated with 2.5\% soy phytosomal thermogel; Group 4, untreated control group.

Abbreviations: HDL, high-density lipoprotein; LDL-c, low-density lipoprotein cholesterol; TC, total cholesterol; TGA, triglycerides; VLDL-c, very low-density lipoprotein cholesterol. 


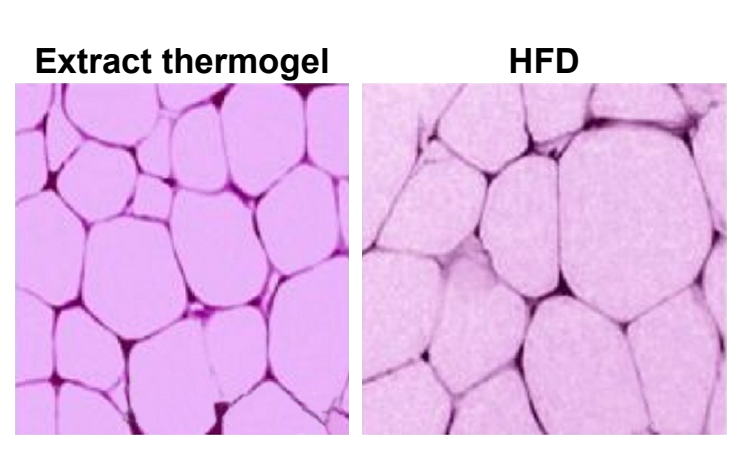

\section{Soy phytosome thermogel}

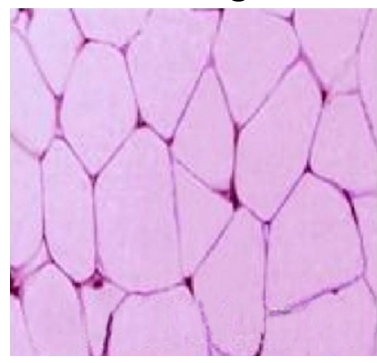

Plain thermogel

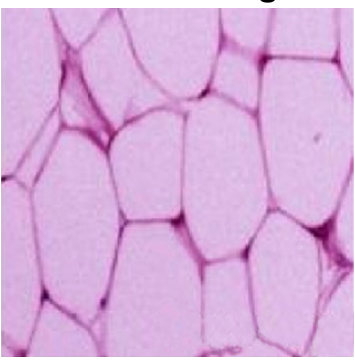

Figure 8 Histological analyses of epididymal white adipose tissue; hematoxylin and eosin (magnification $\times 100$ ). Abbreviation: HFD, high-fat diet.

Although rats were treated topically, lowering effect on the serum lipid profile was observed, which showed slight systemic anti-obesity effect of soy phytosomal thermogel which can be explained by the fact that nanosized particles of phytosome vesicles have a high skin permeation ability that may let it reach the blood circulation showing the cholesterollowering property of orally administered soy proteins. ${ }^{38}$

In conclusion, soy phytosomal thermogel was found to have a local anti-obesity effect on rats' abdomen with slight systemic effect on the lipid profile data.

\section{Conclusion}

In this study, a novel topical drug delivery system of soy extract has been developed in an attempt to investigate the anti-obesity action of soy topically. Phytosomal thermogel of soy extract was formulated and evaluated, and the optimized phytosome formulation was found to have an $\mathrm{EE} \%$ of 99.89 , PS equal to $64.44 \mathrm{~nm}$, and a release percentage up to 92.50 within 2 hours. FTIR study confirmed the formation of a soy-PC complex that was also found to have a high permeation rate profile. The optimized phytosome formulation was then incorporated into the thermogel formulation and characterized for skin delivery suitability.

In vivo study on rats proved that soy extract has the ability to locally decrease the size of adipose cells in the abdominal area of rats with a slight systemic lowering effect on the serum lipid profile. Therefore, topical phytosomal thermogel of soy extract can be considered a hopeful formulation for the treatment of obesity.

\section{Acknowledgments}

Authors are thankful to Nahda University Beni-Suef central lab for providing the facilities to bring out this work and for Professor Dr Mohammed El-Gebaly for his great effort in plant authentication.

\section{Disclosure}

The authors report no conflicts of interest in this work.

\section{References}

1. Adeneye AA, Adeyemi OO, Agbaje EO. Anti-obesity and antihyperlipidaemic effect of Hunteria umbellata seed extract in experimental hyperlipidemia. J Ethnopharmacol. 2010;130(2):307-314.

2. Kwon CS, Sohn HY, Kim SH, et al. Anti-obesity effect of Dioscorea nipponica Makino with lipase-inhibitory activity in rodents. Biosci Biotechnol Biochem. 2003;67(7):1451-1456.

3. Lee BJ, Ryu JH, Kim JW, Park JH, Park JW. The anti-obesity effects of Gambi-hwan extract on obese rats induced by high-fat diet through the expression of UCP-1 and PPAR- $\delta$. Korean J Orient Med. 2007;28(4): 136-147.

4. Jadeja RN, Thounaojam MC, Ramani UV, Devkar RV, Ramachandran A. Anti-obesity potential of Clerodendron glandulosum. Coleb leaf aqueous extract. J Ethnopharmacol. 2011;135(2):338-343.

5. Elnaggar YS, El-Refaie WM, El-Massik MA, Abdallah OY. Lecithinbased nanostructured gels for skin delivery: an update on state of art and recent applications. J Control Release. 2014;180:10-24.

6. Priti L, Heen S. An overview of phytosomes as an advanced herbal drug delivery system. Res J Topical Cosmet Sci. 2013;4(2):65.

7. Lee GR, Shin MK, Yoon DJ, et al. Topical application of capsaicin reduces visceral adipose fat by affecting adipokine levels in highfat-diet-induced obese mice. Obesity (Silver Spring). 2013;21(1): 115-122.

8. Armanini D, Nacamulli D, Francini-Pesenti F, Battagin G, Ragazzi E, Fiore C. Glycyrrhetinic acid, the active principle of licorice, can reduce the thickness of subcutaneous thigh fat through topical application. Steroids. 2005;70(8):538-542.

9. Amin T, Bhat SV. A review of phytosome technology as a novel approach to improve the bioavailability of nutraceuticals. Int $J \mathrm{Adv}$ Res Tech. 2012;1(3):1-15.

10. Moon HJ, Ko du Y, Park MH, Joo MK, Jeong B. Temperatureresponsive compounds as in situ gelling biomedical materials. Chem Soc Rev. 2012;41(14):4860-4883.

11. Kim HJ, Hwang JT, Kim MJ, et al. The inhibitory effect of saponin derived from Cheonggukjang on adipocyte differentiation in vitro. Food Sci Biotechnol. 2014;23(4):1273-1278.

12. Velasquez MT, Bhathena SJ. Role of dietary soy protein in obesity. Int J Med Sci. 2007;4(2):72-82.

13. Lee HS, Nam Y, Chung YH, et al. Beneficial effects of phosphatidylcholine on high-fat-diet-induced obesity, hyperlipidemia and fatty liver in mice. Life Sci. 2014;118(1):7-14.

14. Anderson JW, Johnstone BM, Cook-Newell ME. Meta-analysis of the effects of soy protein intake on serum lipids. New Engl J Med. 1995; 333(5):276-282. 
15. Zhang W, Popovich DG. Chemical and biological characterization of oleanane triterpenoids from soy. Molecules. 2009;14(8):2959-2975.

16. Singh R, Parpani S, Narke R, Chavan R. Phytosome: recent advance research for novel drug delivery system. Asian J Pharmaceut Res Health Care. 2014;2:15-29.

17. Ahmed TA. Preparation of transfersomes encapsulating sildenafil aimed at transdermal drug delivery: Plackett-Burman design and characterization. J Liposome Res. 2015;25(1):1-10.

18. Chen-yu G, Chun-fen Y, Qi-lu L, et al. Development of a quercetinloaded nanostructured lipid carrier formulation for topical delivery. Int J Pharm. 2012;430(1-2):292-298.

19. Freag MS, Elnaggar YS, Abdallah OY. Lyophilized phytosomal nanocarriers as platforms for enhanced diosmin delivery: optimization and ex vivo permeation. Int J Nanomedicine. 2013;8:2385-2397.

20. Das MK, Kalita B. Design, and evaluation of phyto-phospholipid complexes (Phytosomes) of rutin for transdermal application. J App Pharm Sci. 2014;4(10):51-57.

21. Allam AN, Komeil IA, Abdallah OY. Curcumin phytosomal softgel formulation: development, optimization and physicochemical characterization. Acta Pharm. 2015;65(3):285-297.

22. Parmar VJ, Lumbhani AN. Formulation and development of thermoreversible mucoadhesive intranasal in situ hydrogel by using a combination of polymers. Bull Pharm Res. 2012;2(3):167-174.

23. Garg BJ, Garg NK, Beg S, Singh B, Katare OP. Nanosized ethosomesbased hydrogel formulations of methoxsalen for enhanced topical delivery against vitiligo: formulation optimization, in vitro evaluation and preclinical assessment. J Drug Target. 2016;24(3):233-246.

24. Lu C, Liu M, Fu H, et al. Novel thermosensitive in situ gel based on poloxamer for uterus delivery. Eur J Pharm Sci. 2015;77:24-28.

25. Pingali PS, Srinivas P, Reddy BM. Miconazole loaded novel phytosomal topical gels. World J Pharm Sci. 2015;4(10):2305-2320.

26. El-Badry M, Fathy M. Enhancement of the dissolution and permeation rates of meloxicam by the formation of its freeze-dried solid dispersions in polyvinylpyrrolidone K-30. Drug Dev Ind Pharm. 2006; 32(2):141-150.

27. Tan S, Gao B, Tao Y, Guo J, Su ZQ. Antiobesity effects of capsaicinchitosan microsphere (CCMS) in obese rats induced by high-fat diet. J Agric Food Chem. 2014;62(8):1866-1874.
28. Tan Q, Liu W, Guo C, Zhai G. Preparation and evaluation of quercetinloaded lecithin-chitosan nanoparticles for topical delivery. Int $J$ Nanomedicine. 2011;6:1621-1630.

29. Kazmi I, Afzal M, Rahman S, Iqbal M, Imam F, Anwar F. Antiobesity potential of ursolic acid stearoyl glucoside by inhibiting pancreatic lipase. Eur J Pharmacol. 2013;709(1-3):28-36.

30. Joo H, Kim CT, Kim IH, Kim Y. Anti-obesity effects of hot water extract and high hydrostatic pressure extract of garlic in rats fed a high-fat diet. Food Chem Toxicol. 2013;55:100-105.

31. Centis V, Vermette P. Physico-chemical properties and cytotoxicity assessment of PEG-modified liposomes containing human hemoglobin. Colloids Surf B Biointerfaces. 2008;65(2):239-246.

32. Varshosaz J, Pardakhty A, Hajhashemi VI, Najafabadi AR. Development and physical characterization of sorbitan monoester niosomes for insulin oral delivery. Drug Deliv. 2003;10(4):251-262.

33. Wang X, Guan Q, Chen W, Hu X, Li L. Novel nanoliposomal delivery system for polydatin: preparation, characterization, and in vivo evaluation. Drug Des Devel Ther. 2015;9:1805-1813.

34. Zhang J, Tang Q, Xu X, Li N. Development and evaluation of a novel phytosome-loaded chitosan microsphere system for curcumin delivery. Int J Pharm. 2013;448(1):168-174.

35. Xu X, Shen Y, Wang W, et al. Preparation and in vitro characterization of thermosensitive and mucoadhesive hydrogels for nasal delivery of phenylephrine hydrochloride. Eur J Pharm Biopharm. 2014;88(3): 998-1004.

36. Phatak AA, Chaudhari PD. Development and evaluation of nanostructured lipid carrier (NLC) based topical delivery of an anti-inflammatory drug. J Pharm Res. 2013;7(8):677-685.

37. El-Menshawe SF, Hussein AK. Formulation and evaluation of meloxicam niosomes as vesicular carriers for enhanced skin delivery. Pharmaceutical Dev Technol. 2013;18(4):779-786.

38. Wilson TA, Nicolosi RJ, Kotyla T, Fleckinger B. Soy protein without isoflavones reduces aortic total and cholesterol ester concentrations greater than soy protein with isoflavones compared with casein in hypercholesterolemic hamsters. Nutr Res. 2007;27(8): 498-504.
International Journal of Nanomedicine

\section{Publish your work in this journal}

The International Journal of Nanomedicine is an international, peerreviewed journal focusing on the application of nanotechnology in diagnostics, therapeutics, and drug delivery systems throughout the biomedical field. This journal is indexed on PubMed Central, MedLine, CAS, SciSearch ${ }^{\circledR}$, Current Contents ${ }^{\circledR} /$ Clinical Medicine,

\section{Dovepress}

Journal Citation Reports/Science Edition, EMBase, Scopus and the Elsevier Bibliographic databases. The manuscript management system is completely online and includes a very quick and fair peer-review system, which is all easy to use. Visit http://www.dovepress.com/ testimonials.php to read real quotes from published authors. 